\title{
A Proposed Model to Behaviourally Pricing Risk
}

\author{
Jacques Peeperkorn, Yudhvir Seetharam* \\ University of the Witwatersrand, South Africa \\ *yudhvir.seetharam@wits.ac.za
}

\begin{abstract}
To imagine that asset pricing is not dependant on behavioural heuristics and game theory, we are required to reduce the definition of the participants to that of utility maximising, risk-averse, uniform automata. This study examines this statement through an application of behavioural theory that speaks to the ability of investors to perceive risk, as well as the interactive effects of game theory to distort the perception of risk from exogenous variables to that of endogenous probability beliefs. We present a foundation for a state-space model, such as a Kalman filter, to be used in pricing risk.
\end{abstract}

Keywords: Asset Pricing, State space mathematics, Behavioural Finance, Risk

\section{Introduction}

The treatment of risk as a probability belief dictated by behavioural heuristics is a significant divergence from traditional pricing theory. As a precursor to the development of an asset pricing model, this study begins with establishing a theoretical behavioural profile to describe how investors are likely to perceive risk. Understanding how a typical investor perceives risk will allow one to identify what causes demand and supply fluctuations in the market, and hence price fluctuations (Slovic, 2000). Thus, in order for an asset pricing model to accurately capture the risk-return relationship, it must be sensitive to how an individual perceives causation (the cause-effect relationship). In this review article, we argue that an asset pricing model should include a learning based component in its estimation; and provide a foundation for the use of a Kalman filter in this regard. The literature presented provide a rationale as to why a learning-augmented model might be considered superior, as it highlights the importance of the effect of human behaviour at both the individual level, as well as the group level. To proceed from the basis outlined above, questions fundamental of asset pricing in the context of current applications are considered, namely:

- How are risks identified, processed and thus priced by individuals?

- What risks are relevant to asset pricing?

- Are all non-systematic risks diversified?

- Are both homogenous and heterogeneous behavioural predispositions to investors appropriately considered?

The results of this investigation dictate that an appropriate model should follow from the single (systematic) risk factor design of the traditional capital asset pricing model (CAPM), as seen in Equation 1 below, where the expected return of share $i$ is a function of the risk free rate $\left(r_{f}\right)$ and the product of the exposure of the share to the market $(\beta)$ and an equity risk premium $\left(r_{m}-r_{f}\right)$.

$$
E\left(R_{i}\right)=r_{f}+\beta\left(r_{m}-r_{f}\right) \quad\{1\}
$$

The fundamental departure from the traditional CAPM comes in how, as a cross-sectional collective, the risk representative slope coefficient of the linear regression model is specified, as well as how it is described to evolve over time. Further, this risk factor should be considerate of specific individual and interactive behavioural characteristics, which can be seen to represent the typical investor. The result is a form of linear regression which is estimated through a recursive learning-augmented algorithm and the use of state-space mathematics. This review proceeds as follows. We provide a qualitative outline of our argument for the inclusion of a learning augmented approach to pricing risk. This outline includes discussion around probability beliefs, risk and utility. Chapter 3 expands this discussion consider how agents interact within this framework, with Chapter 4 providing some points of statistical consideration in building such a model. Chapter 5 concludes.

A Qualitative Analysis: The perseverance of pricing errors to traditional asset pricing models remains at the forefront of financial literature today, particularly where portfolios are sorted by size and book-tomarket ratios. The extents to which these pricing anomalies are observed across markets are considered 
to be too common to be ignored or explained away as outliers to traditional pricing theory. Noted by Fama and French (1993) on American data, Chiao and Hueng (2005) on Japanese data and Basiewicz and Auret (2010) on South African data, the extent to which traditional asset pricing models fail to capture relevant market risk completely is clearly evident. Literature has explored these pricing inefficiencies, looking to capture these unexplained risk events by isolating and regressing returns on fundamental risk drivers (Chen, Roll, \& Ross, 1986; van Rensburg, 1999). This approach is in line with a rational expectations model, such as the CAPM, where the central premise of pricing risk is maintained by considering non-diversifiable systematic risk as the only rational exposure for which abnormal returns can be generated. Further, the approach also addresses the practical limitations of a single risk factor to appropriately represent a complete cross-section of market variables, in line with the argument of Roll (1977). In Equation 2 below, the expected return of share $i$ is now a function of $n$ additional factors apart from the share's exposure to the market.

$$
E\left(R_{i}\right)=r_{f}+\beta_{1} R P_{1}+\beta_{2} R P_{2}+\beta_{3} R P_{3}+\cdots+\beta_{n} R P_{n}
$$

The results have however been mixed, and whilst there has been notable evidence of the success of this multifactor approach in reducing prediction errors, none of these models have achieved an unequivocal triumph of the asset pricing 'problem'. In contrast to the efficient market view in which asset prices are not considered linearly dependent on past observations, studies that examine these pricing anomalies over time have drawn time-series explorations as possible limitations to traditional asset pricing theory (Jegadeesh, 1990; Jegadeesh \& Titman, 1993; Carhart, 1997). However, the success of these conditional extensions of the CAPM to consider cross-sections of fundamental risk is shown to add little to no value when tested in light of time-series risk variation (Lewellen \& Nagel, 2006). As these studies show that a simple extension of the CAPM to include further cross sectional risk factors is insufficient, an alternative strand of literature combines the time series approach with a strong behavioural flavour. Support for a time-series approach in considering the asset pricing problem has had strong empirical support, having been documented by authors such as Harvey (1989), Ferson and Harvey (1993) and Jagannathan and Wang (1996). In more recent extensions of the time-series approach to asset pricing, Adrian and Franzoni (2009), Huang and Hueng (2009) and Trecroci (2013) provide evidence of exploiting this volatility through state-space modelling. We provide a foundation for the use of a Kalman filter (Equation 3 below), in the subsequent literature review.

$$
E_{t}\left(R_{t+1}^{i}\right)=\beta_{t+1 \mid t}^{i e} E_{t}\left[R_{t+1}^{M}\right]
$$

Where $\beta_{t+1 \mid t}^{i e}=E_{t}\left(\beta_{t+1}^{i}\right)$. Here, the expected return is proportional to the expected risk factor loading, which in itself, depends on the stochastic evolution of the unobserved beta. In Equation 4, beta evolves according to some stochastic specification, conditional on exogenous variables $y_{t}$. If it is assumed that the average of these conditional variables is zero, then $B^{i}$ is interpreted as the long run beta. Further, if this long run beta is assumed to be unobserved, then investors would have to form expectations about the riskiness of the asset in question. This specification is given in Equation 4.

$$
\beta_{t+1}^{i}=\left(1-F^{i}\right) B^{i}+F^{i} \beta_{t}^{i}+\phi^{i^{\prime}} y_{t}+u_{t+1}^{i}
$$

Where $u_{t+1}^{i}$ is idiosyncratic risk, which does not have to be normally distributed (Carlin, Polson and Stoffer, 1992). In a subsequent study, we provide empirical tests of our hypothesis. The point of departure from the afore mentioned authors' considerations of time variant model design rests with the definition of risk itself, a point which is elaborated upon below.

\section{Establishing probability beliefs}

The movement to consider an alternate risk exposure measure to that of a singular systematic risk variable is not new in economic literature. Asset pricing models have used the assumption of a complete asset universe, or at least a proxy thereof, in order to price assets as calculated by their risk exposures. This has been done by calculating their correlation to a "complete or accurate proxy thereof" market portfolio (Roll, 1977). Assuming one has a perfect proxy of the market portfolio, this portfolio's correlation with other assets can be considered causative - changes in return of the one portfolio may cause changes in the return other asset. This limitation however, is highlighted in Roll (1977) which points out with unforgiving assertion that a complete market portfolio is as unlikely to define, as it is to test. This leaves the ability to perceive market correlation as an effective proxy for fundamental risk as potentially undermined, and practically unreliable. With this in mind, we consider an alternative approach that looks to price risk based upon decision making under uncertainty, being relevant to both 
systematic and non-systematic risks, and captured through investor probability beliefs. Instead of defining the relevance of risk by rational expectations, the behaviour of investors is developed through observation of the interaction of demand and supply, which is used to inform the true nature of investor probability belief. The rationale behind this takes direction from a large body of work into the psychology of investors, and the possibility that behavioural heuristics, in conjunction with social interactions, provide a sufficient deviation from rational efficient market theories (Muth, 1961). In effect, we consider that risk exposure, whilst informed by exogenous factors, manifests as endogenous output of a feedback model.

To establish the concept of risk in this pricing model, one must explore the nature of the trader rather than the assets traded. Indeed, in a market, it is only what another will pay which determines the value of an asset and the perception of future value that determines that asset's price stability and hence risk. The perspective of market dynamics shifts the focus of an observation of risk from cross-sectional exogenous variables to a time-series variation of investor demand and supply. This change in viewpoint does not imply that exogenous risks are irrelevant, but instead they are considered too difficult to observe. Further, if these exogenous risks are observed, their effects are not expected to add unbiased informational value once the confounding effects of a behavioural market theory are taken into account (a concept built upon later). The cross-section of risk drivers is considered representative of the market's collective probability belief and the development thereof is subject to specific behavioural biases at both the individual and market level. Fundamental risk is thus collectively referred to as variation around the mean objective probability distribution, a distribution which is generally unknown to the investor, therefore leading to the formation and use of subjective probability beliefs (Markowitz, 1991). An investigation into the manner in which investors learn about risk, and therefore form probability beliefs themselves is thus required. Specifically, the question at hand, and one that is central to developing a behaviourally defined pricing model, is how individuals infer a causal relationship between news and events that they observe and the effect of an asset in which they invest.

Risk in light of the human predisposition: In order to price assets, one needs to consider the riskreward relationship, where investors are compensated for excess risk exposure. One might say that as risk levels vary, so too do prices vary. If one can identify the variation in risk, one can hypothetically identify (predict) the variation in return, a premise by which many asset pricing models are established. Risk is an abstract measure of the likelihood of stability; it is how likely one's exposure might lead to a drop in asset price (Slovic, 2000). In a sense then, risk drives price because the variability of the outcome is personified as risk affects price. The two are circular in a sense. Thus what, one might ask, is risk? Barring any finer points in the philosophy of finance, we define risk as an individual's perception of change. In order to price asset returns, one must understand the perception of risk, and the perception of risk is the product of cause and effect reasoning.

If fundamental movements change the value of assets and prices move accordingly, there is no risk involved but simply a cause and effect. Risk is only present when an opinion is created regarding said movements and is introduced when there is doubt in the belief that the event may happen. Thus, risk is a manifestation of an individual's past experience leading that individual to reason a cause and effect relationship (Sitkin and Pablo, 1992). Whilst fundamentals are informative, cognitive bias skews market behaviour from a purely efficient form to a type of secondary asset market whereby prices are driven through the type of behavioural anomalies described above. A separation is therefore made between the quantity of loss experienced through the fundamental drop of prices, and that of the confounding effect of cognitive bias and associated trends in the movement of prices. It is this expansive movement which exists only in the presence of opinion. One might therefore consider in light of traditional pricing models that the risk attributable to endogenously driven equity returns is a product of opinion, and only that which is endogenous to the supply and demand of equity markets is by definition a fundamental risk. Any consideration of endogenously driven risk must be a product of some or other form of bias in the process of reasoning and inference. Importantly, these factors are necessarily informed by fundamental movements, and thus must be considered in the presence of a model which prices assets based on exposure to fundamental risk in light of the human predisposition.

Thus, asset pricing needs to consider the importance of exogenous risk asset factors and the development of their subjective interpretations as dictated by behavioural heuristics of both the market and market participants. The description of subjective probability beliefs is easily extended beyond the individual when considered at the market level. If one views market movements as a form of economic game, risk 
takes on the following form: The individual's perception that something will change unexpectedly is based on a perceived cause. While the outcome is based on causal reasoning, it is also based on the subjective interpretation of other market participants who themselves are subject to the very same behavioural predispositions. To profit from such a change, the individual needs to be aware of both the fundamental risk of the asset and how other investors would perceive this change in risk. Thus, that individual's view of an asset's expected return must also consider some form of learning from market participants as a necessary risk factor. This learning component can be viewed as a probability belief of causal reasoning and the subjective interpretation of other market participants. If the actual outcome deviates from what was expected, then the cause of the expected outcome is viewed as risky. Thus, risk can be seen as a derivative of probability beliefs of market participants, which is directly represented in the returns to assets.

Considering that market prices are driven by investor demand and supply, what drives stock prices is ultimately the cumulative market perception of risk and return. That is to say, whilst investors may consider forward looking expectations, this causal reasoning is necessarily informed by past observations. Further, they can be continually updated in a dynamic learning framework. Reading the above as a behavioural description of investor mechanisms that ultimately drive demand and supply establishes the first condition of a behavioural pricing model. In order to be considerate of potential biases in the way in which investors arrive at a subjective probability belief, a dynamic state-space asset pricing model that incorporates learning is required. This leads to the consideration of a Bayesian type model $^{1}$. The Bayesian approach provides a mathematical rule to explain how you should change your existing beliefs in light of new evidence. The theorem can be viewed as a mathematical description of how probability beliefs about the future are updated through updating past observations. Where the Bayesian model fails, is in its unbiased probability updates that do not allow for dynamic learning conditions. In order to consider a Bayesian statistics based model that allows for the importance of a particular observation to be influenced by learning, a Kalman filter is natural model progression from a recursive Bayesian model.

Diversification and allocative efficiency to a market utility theory: The behavioural description of probability beliefs and the nature in which it is expected to evolve through learning presents a contrast to traditional rational expectations. Specifically, the CAPM and many of its extensions base the pricing of risk on, amongst others, the assumption that investors are myopic risk averse traders who hold assets in accordance with modern portfolio theory (MPT) (Markowitz, 1952). This suggests that investors hold a portfolio of stocks to diversify idiosyncratic risk, a concept on which theory assumes that investors hold a minimum variance market portfolio in equilibrium. The result is that popular asset pricing models, including the CAPM and many of its extensions, only price systematic risk, as it is argued that idiosyncratic risk can and should be diversified away. As a result, investors should not be able to earn excess return over the market portfolio for taking on excess diversifiable risk. This section contends that these assumptions are non-descriptive of individual investor behaviour, and as such, a model that does not consider the relevance of risk beyond that of systematic risk exposure is very likely to be incorrectly specified. Evidence presented here suggests that, in contrast to traditional asset pricing theory, investors may not tend to perfectly diversify their equity holdings. This tendency is in direct contrast to the riskaverse basis of the CAPM. As such, an alternate explanation of risk appetite is considered under a behaviourally inspired theory of utility. This descriptive model of how decisions are made under uncertainty is presented as a basis for why probability beliefs are expected to price risk beyond systematic risk considerations alone.

Towards a utility theory: Various theories assuming under-diversification predict that idiosyncratic risk is positively related to expect stock returns in the cross-section. This implies that investors are expected to be compensated for bearing idiosyncratic risk, contrary to traditional portfolio and pricing theory (Markowitz, 1952). The concept is certainly not new, and previous notable advocates of this theory of idiosyncratic relevance include Levy (1978), Merton (1987) and Malkiel and Xu (2002). Fu (2009) suggests that the concepts of risk and return borne out of MPT are incomplete due to their assumptions about a uniform rational investor universe. Evidence to suggest that investors are rewarded for taking on idiosyncratic risk through excess returns suggest that any complete multifactor asset pricing model must necessarily provide scope to price assets based on their exposure to a combination of systematic

\footnotetext{
${ }^{1}$ A recursive Bayesian model is a predictive model which updates future predictions based on Bayes' Theorem in a time-series environment.
} 
macroeconomic risk factors, as well as microeconomic idiosyncratic risk factors, all of which are expected to be subject to individual interpretation.

In extensions of Rabin's (2000) theory, the theory of concave utility functions results in the marginal utility of wealth diminishing at large rates. Rabin and Thaler (2001) suggest that people will not be averse to risk involving monetary gains and losses that do not alter lifetime wealth enough to affect significantly the marginal utility one derives from that lifetime wealth. This provides a possible behavioural rationale for markets that may experience some fluctuations that deviate from absolute efficiency in spite of an environment with perfect information. Certain pricing errors are expected to exist, which is in line with an adaptive market, and fluctuation around perfect allocative equilibrium is descriptive of a stable, selforganised system. Building upon this description of non-equilibrium stability, Kandel and Stambaugh (1991) find that due to the varying circumstances of individuals and their degree of intent when investing in equity markets, the coefficient of relative risk aversion cannot be expected to be consistent. Importantly, these findings are indicative of a dynamic risk factor model, a finding that dictates that any asset pricing model that is appropriately descriptive of expectant human behaviour must be necessarily dynamic by nature. As investor circumstances vary, and the interpretation of risk is thus non-uniform across investors and time, the description of a risk factor takes on a time-variant nature of a dynamic probability belief model.

A behavioural expansion to the market: A large body of research into the time-varying effects of risk exists to support the notion of a time-varying investigation as pointed out above. The question then is, if probability beliefs are indicative of investor behaviour and the market is considered as a collective trading body, why then has momentum not formed the basis for a time-series dependent risk variation explanation. The use of momentum has been tested to great extent in capital asset pricing (Jegadeesh 1990; Carhart, 1997; Jegadeesh and Titman 1993, 2002) and whilst these authors note the potential strength of a momentum factor in explaining returns, it has not been found to solve the asset pricing problem. Momentum trading generally follows a majority rule, one that for the most part conforms to a uniform beliefs system. This considers that all traders conform to a single majority opinion regarding probability beliefs and thus undermines the individuality of a single trader. The economic value of heterogeneous beliefs is empirically demonstrated at the individual level by Malkiel and Xu (2002) which notes the importance of considering risk exposure in excess of systematic risk, the value of which is shown as a feature of greater market interactions through the contrarian strategy study of Lakonishok, Shleifer and Vishny (1994).

Minority rule: Game theory observes the behaviour of individuals as they interact in various environments. The consideration of game theory in its simplest form leads to the establishment of equilibrium behaviour, most often presenting a solution of how the persuasions of the majority come to rest in light of the likely expected behaviour of each other participant. Whilst this is a bold simplification, the study of how behavioural patterns come to equilibrium is a useful simplification for an economic study of asset pricing. In this section, the concept of the minority rule is considered for its relevance in undermining the majority rule of momentum, and how the behavioural contrast is relevant to a dynamic model specification. That is to say, the concept of a self-organised stable market which does not settle into a static behavioural equilibrium is explored. Market participants are expected to shift their positions according to the utility theory of loss-aversion as opposed to risk-aversion, leading to a market that has freedom to shift dynamically between risk profiles. Dubbed the El Farol problem, Arthur (1994) describes how utility maximising individuals will, in certain circumstances, find it beneficial to be in the minority. This is much like considering the benefit and desires to be a buyer in a seller's market, and vice versa. In his model, the problem is a form of game that rewards individuals who can best guess majority intentions. The model considers how individuals use various rules of thumb to try and best guess the probable movements of the masses.

This presents a complication to a behavioural pricing model, as the decisions of the individuals are not based solely on the fundamentals of the consumption variables in question. These fundamentals determine whether the market (game) is entered, beyond which the decision making process is further complicated as value is expected to be greatly influenced by the interpretation of market participants and their various expected probability beliefs. Only once the merits of the consumption variables in question have been established and are considered to generate sufficient utility to the market, will the game be entered. Once the market as a whole establishes consensus of the benefits of the variables, the decision to invest becomes more complex, as the decision-making is now a function of others' decisions as well. 
Whilst the notion of asset prices deviating from fundamentals may be considered irrational, one must consider that whenever there is a question of uncertainty of multiple individual participants, the prospects of game theory need to be considered. The application of game theory to the economy is an interesting and complex one, as the economy can never be considered to be a pure minority game, nor should it be assumed to be void of minority game considerations. Indeed both minority and majority game theory should be considered. An interesting result of defining the market as dynamic and selforganised is that it implies that traders are required to continuously adapt to their environment. Investors are required to continue learning and whilst trends in behaviour may persist over periods, they are not expected to be stable in perpetuity. Thus no model which is designed to price risk in a static market description can be expected to succeed. In their research, Neely, Weller and Ulrich (2009) display that whilst particular technical trading rules can be seen to generate value, excess returns to these market positions are diminishing over time as markets adapt. The adaption of market positions is considered by the authors to be too slow to be indicative of an efficient market.

\section{Behavioural evolution}

The pricing anomalies described in Daniel and Titman (1999) do not conform to traditional risk measures and are described as being endogenous to the system. It is therefore unrealistic to assume that all possible endogenous risk drivers can be diversified away and thereby be excluded from a multifactor pricing model as is suggested by Chen et al. (1986) when referring to microeconomic factors. If risk measures fail to price assets correctly based on behavioural heuristics, it is necessary to include a set of internal risk factors designed to capture these risks. Whilst Coval and Shumway (2005) present evidence that certain behavioural heuristics leading to pricing anomalies are priced out by rational traders in a short time, evidence presented by Daniel and Titman (1999), amongst others, suggests that the potential presence of a behavioural influence on asset pricing can be expected to be persistent.

An adaptive market: A key defining feature of economic agents is that their decisions depend upon their expectations of beliefs about the future (Hommes, 2001). Hommes (2001) adds to this introductory statement by quoting Keynes (1936) which questions objective rational valuation of assets in favour of an investor belief system that considers mass market psychology not unlike that described in the study of game theory. Keynes (1936) makes his point through a parable which describes a beauty contest used to describe the financial markets. The parable suggests that in order to predict the outcome of a beauty contest, objective beauty is not at all important, but knowledge or prediction of others' perceptions of beauty is much more relevant. To extend this parable to a single factor asset pricing framework, it would suggest that in order to best predict the value of an asset, one must understand the market opinion of that asset. In order to do this, a probability belief needs to be established. The ability to price financial assets accurately is often assumed in literature as a matter of course, an assumption where the EMH has dominated financial research. Potters, Cont and Bouchard (1998) label the pursuit of asset pricing as being, in general, difficult to assess quantitatively as the "true" value of an asset is difficult to determine. The authors go so far as to suggest that the concept of efficient pricing may be an empty concept altogether. Whilst this opinion may be extreme, research based on identifying specific causal risk factors both microeconomic and macroeconomic in nature suggests that whilst there is value to the pursuit, it cannot be viewed as a complete description of the market, nor does it fully capture how investors price assets.

One of the limiting factors to this testing is the ability to observe the amount of wealth controlled by irrational investors and their specific tastes. This is by definition expected to be a varying figure which is only observable in hindsight. Further, even when seen in hindsight, Daniel and Titman (1999) argue that a model developed based on rational expectations would fail to adapt and observe these heuristics and price them into the market accordingly. The second issue is that, based on this dynamic nature of influential behavioural heuristics, pricing models which price the heuristics with the benefit of hindsight will improve on traditional pricing models. These considerations to heterogeneous beliefs lead to the pursuit of a market model which considers the question of informational efficiency, as opposed to allocative efficiency. As agents in these markets are expected to follow probability beliefs in lieu of difficult to observe fundamental risks, a test of whether assets are priced to reflect efficiently their fundamental risk exposure is not relevant. Rather, informational efficiency, which suggests that market returns should be difficult to forecast due to a lack of arbitrage opportunities, is considered. By this extension, an appropriate model design is one which, when correctly specified, observes no excess 
returns to a collective market belief of risk, where all risks are plausibly relevant (based upon the behavioural perception of investors).

Traditional long run beta would be suggestive of a traditionally defined rational agent market place if this risk measure fully explains asset prices. However, evidence suggests that there are unexplained returns statistically observed as prediction errors. The assumption that excess returns are actively priced out under an AMH framework is support by Neely et al. (2009) which concludes that excess returns are eroded over time, finding that markets do adapt to evolutionary selection pressures. Whilst their study was concerned with the testing of technical trading rules in the foreign exchange market, their results build on the premise that market participants' behaviour adapt over time and that the market is actively learning from observation of its participants. The result is that the tendencies of the market dynamically adjust over time, resulting in fluctuations in demand and supply and thus in the perceived risk of assets.

The survival of all in free markets: Friedman (1953) describes market efficiency by an argument that suggests that irrational traders will continue to lose money, and will not survive. The effect of this argument being that those traders will not have a marked or persistent influence on long-run asset prices. Kogan, Ross, Wang and Westerfield (2006) show how this is not necessarily the case, and that the effect of irrational traders on market prices is not so easily explained away. In establishing the resilient nature of traders, Kogan et al. (2006) provide evidence to suggest that even where survival of irrational traders is threatened through a diminishment of their wealth, these traders can continue to have a significant impact on asset prices. In the case of momentum strategies and resilience to short term or immediate reversals, rational trading may involve following irrational trading. This is in support of the view of De Longe, Shleifer, Summers and Waldman (1991) who suggest that rational traders may amplify irrational trading by buying ahead of feedback traders, thus profiting off of the momentum. This makes sense from a game theory perspective, especially if one ascribes superior trading knowledge to these "rational traders", who would then be able to close their positions before prices reverse.

Shiller (2003) echoes these perspectives in a depiction of a market composed of smart versus ordinary investors. In an alternate perspective, he finds support for behavioural theories that suggest that nonrational risk perception and associated momentum style trading can be considered inherently human and not uncommon. De Longe et al. (1991) present a complimentary view to this theory, suggesting that whilst the effect of irrational traders is diminished as their total wealth diminishes, this state is merely transitional. De Longe et al. (1991) show that as prices recover to be based on rational beliefs, the wealth of irrational traders can grow at a faster rate than that of rational traders, allowing them to recover and survive. Kogan et al. (2006) suggest that this is based on unrealistic premises, yet offer explanation and economic proof to show how irrational price influence can survive in spite of diminishing wealth. The model considers the final wealth (as opposed to interim movement) of a trader as being a fundamental point of reference. This is consistent with literature whereby investors are expected to be loss averse (as opposed to traditionally defined risk averse). Through a logarithmic preference investigation, the authors submit that an irrational trader's influence on prices does not decay as quickly as his relative wealth share, and thus his influence on market prices are expected to be persistent.

A single risk factor: As discussed previously, a single risk coefficient (beta) is suggested as a proxy for the true risk drivers of assets, be they fundamentals, unique non-systematic variables, behavioural heuristics or macroeconomic variables. Here the behavioural effects of heterogeneous market considerations are formalised into a model that retains the probability belief definition as a single evolutionary factor through a feedback model design. The treatment and distinction of economic variables, as described by Chen et al. (1986), is to be explored and built upon in light of probability beliefs. In this description of market dynamics, even macroeconomic drivers form part of the financial market's feedback loop. Specifically, this market endogeneity is comparable to a negative feedback model. The inputs can be thought of as fundamental market variants, noise can be interpreted as heterogeneous information and its subjective interpretation thereof, and the feedback as participant interactions subject to noise. Building on an economic interpretation of this, decision making agents in the market can be thought of as converting noisy raw information into clean probability beliefs which are observable in the market through the effects of supply and demand. The initial interpretation of raw fundamental information serves as a model input from which an initial probability belief can be built. The effect of participant beliefs is fed back into the model to affect an endogenously informed probability based on individual and interactive factors. Thereafter, the effect of these probability beliefs presents an important consideration for interpreting the responses of other investors in the market. This is all fed back into the 
decision making system of rational economic agents, resulting in a negative feedback loop which ultimately drives demand and dictates output. In this way, the output of a market as observed through share price returns is the result of a complex negative feedback system of information and the interpretation thereof.

\section{Into model design}

Correlation versus causation: A qualitative description: Empirically observed covariation is a necessary, but not sufficient condition for causality (Aldrich, 1995). Whilst correlation serves as a commonly observable feature of regression analysis in financial time-series, caution must be observed when using it to define risk exposure. Correlation guarantees neither an implied causation, nor a common causal driver or link. Statistically, investigations into causation which are based on observing correlation are naturally susceptible to type 1 error, in that the causation can be erroneously implied based on a statistical observation of correlation. Thus, using correlation to dictate investment profiles opens up the possibility of miss-specifying variable interactions, and thus failing to adequately capture the risk-return relationship. The question then begs: Why does the culture of correlation driven methodology continue to be so common? The simple answer to this is that correlations are easily observable through regression analysis, where as causal interactions require a qualitative justification along with a quantitative correlation observation in order to infer their existence due to the difficulty in isolating causal event observations. The CAPM and its conditional variable expansions, as well as arbitrage pricing theory (APT) models, extend this investigation into preselecting cross-sections of qualitatively justified risk variables and then consider the correlative implications.

Sensitive to the limitations of describing causative relationships through correlation based regression analysis, an alternative perspective is taken. Specifically, the approach in this study shifts the point of causal analysis from the idiosyncratic variables to that of economic demand and supply. This approach places regression analysis at the focal point of that which directly drives asset prices. Thus, asset price movements and the associated risks surrounding equity investment are observable by a traditional correlation measure as far it tracks the influence of traders and how they enforce their belief on the market. If this represents the market condition, the correlation of a risk coefficient that is evolutionary provides an appropriate proxy for causation. This design is both similar and different to traditional theory. Whilst a single risk variable is considered, it is not a collective cross-section of risk exogenous exposures, but rather dependant on the time-series evolution of endogenous market risk through probability beliefs. The separation of probability belief evolution from market observations is theoretically based in behavioural assumptions and practically handled through state-space regression analysis. The issue in question here is the extent to which such a model has the potential to succeed considering real world applications and further, not simply where there are limitations to the accuracy, but where these limitations may have the potential to obscure observations of genuine causally driven correlation. We leave this issue to future research, where we empirically apply a Kalman filter to explain returns.

Filimonov and Sornette (2012) note that as markets become more integrated, they appear to be less reliant on exogenous news about fundamentals and rather are seen to increasingly react to endogenous triggers. Filimonov and Sornette (2012) find over the period 1998 to 2010 on the Standard \& Poor 500 that endogeneity as a driving market force of market activity increased significantly, with the amount of market activity that could be linked to exogenous information falling from 70\% in 1998 to less than $30 \%$ by 2007. The trouble with endogenously defined risk is how to identify and price it. The proposed solution to this problem rests with probability beliefs built through the use of a Kalman Filter to incorporate a dynamic learning model. The implication to this is explained as a single risk factor that varies linearly in a stepwise fashion.

Correlation versus causation: Statistical considerations: The traditional CAPM falls prey to a concern surrounding model design when calculating the correlation between beta and the market. As beta represents a collective of all systematic risk variables in cross-section, correlations may be biased due to an ecological effect. That is, where individual variables are not isolated for observation, the combined (or ecological) effect is to bias the observations and thus undermine theoretical inferences. Ecological correlations tend to be numerically larger than that of actual individual correlations and the conjecture of scenarios where they can be considered to be mathematically equivalent is rejected (Robinson, 2009). A higher biased projection of ecological correlation to beta might serve as a possible explanation for its 
inability to capture risk (as it would be downwardly biased). Higher bias in correlations is expected to result in a reduced ability to pick up tail risk, as well as idiosyncratic risk not otherwise arbitraged away, resulting in unexplainable excess returns. Thus it is submitted, for models which base exposure to risk as interpretations of observed correlations, every effort must be made to achieve, or at least approximate, a study of individual correlations. When ecological correlation over-estimates correlation, variation from the mean is by implication underestimated (Robinson, 2009). Many extensions to the traditional CAPM circumvent the errors associated with ecological correlation bias. A point of contention for this approach from a correlation-causation perspective is still drawn however. The identification and isolation of these extended risk variables poses complications to model specification, all the while implicitly imposing a continued degree of ecological bias, as it is impossible to specify all risk individually. This issue can be viewed as a corollary to the market proxy specification problem of Roll (1977), in that if one cannot be expected to compile an appropriately inclusive collective systematic risk proxy, how can one expect to efficiently isolate individual considerations.

Under the traditional CAPM framework, this grouping of market factors that may influence the fundamental value of an asset will result in the correlations being biased away from their true values. Many studies into multifactor analysis move to correct for this correlation bias implicitly, but as noted above, not only are these models extremely difficult to specify, they have a tendency to improve, but not solve the asset pricing problem. This study therefore takes an alternate route to dealing with this correlation issue, counter intuitively, by moving back towards a single factor model. The method in which this is attempted views correlations as linearly dependent on observation and learning in a time-series manner, as individuals are presumed to form probability beliefs which serve as single risk measures used to influence demand. Considering risk as a time-varying probability belief allows the model to be sensitive to interactions of market participants and thus the endogenous influence of demand and supply. Empirical evidence from Lewellen and Nagel (2006) is considered to suggest that conditional CAPM extensions as exogenous time-series models do not prove to improve on asset pricing. These findings underline further the limits to correlative model testing from an exogenous risk variable perspective. This time-series treatment under behaviourally considerate learning based evolution, whilst theoretically justified, is not dissimilar to the learning models successfully implemented in similar studies of time variant Bayesian risk models (Adrian \& Franzoni, 2009; Huang \& Hueng, 2009).

\section{Conclusion}

Whilst the theoretical question at hand is one that tests for the relevance of a behaviourally sensitive asset-pricing model, the literature presented is structured to outline the question of whether the drawbacks to market pricing efficiency exist due to a misspecification of existing popular pricing models. The proposed model rejects absolute risk aversion in favour of loss aversion as a utility theory, which broadens expectant investment behaviour beyond perfect diversification. The width of cross-sectional risk consideration is expanded further through the consideration of negative feedback and how market interactions are relevant to establishing probability beliefs. These compounding effects make an investigation directly into the cross-section of returns a task that is likely too complex to be considered practically viable. Instead, the deductions of Keynes (1936) are adopted and the task of establishing the true objective value of an asset is rejected in favour of a single probability belief that is dependent on endogenous interactions to determine investor behaviour. The time-variant nature of probability beliefs is based on heterogeneous beliefs which investors are expected to learn about in a manner subject to bias and not expected to be ex post perfectly rational. A Kalman filter is suggested to be applied to asset pricing for its ability to allow for an unknown variable, such as a probability belief, to evolve as an autoregressive function, whilst allowing the prediction of this risk variable to be updated from period to period through the application of an observation equation. Future steps of the procedure use the observation step to analyse the strength of probability belief prediction and learn from any mismeasurement accordingly. As the principles of behavioural learning described are applied as universal governance to this behavioural inspired model, it is predicted that this learning function will help to reduce pricing errors. Our follow up study tests this hypothesis and provides evidence of the efficacy of a behaviourally inspired model for pricing risk. Further, with the inclusion of a learning element to determining risk, the gap between the divergent schools of traditional and behavioural finance begins to close. For the practitioner, an understanding of how investors perceive and price risk enables better judgement on evaluating investment decisions. 


\section{References}

Adrian, T. \& Franzoni, F. (2009). Learning about Beta: Time-Varying Factor Loadings, Expected Returns, and the Conditional CAPM. The Journal of Empirical Finance, 16(4), 537-556.

Aldrich, J. (1995). Correlations Genuine and Spurious in Pearson and Yule. Statistical Science, 10(4), 364376.

Arthur, B. W. (1994). Inductive Reasoning and Bounded Rationality. American Economic Review, 84(2), 406-411.

Basiewicz, P. G. \& Auret, C. J. (2010). Feasibility of the Fama and French three factor model in explaining returns on the JSE. The Investment Analysts Journal, 71, 13-25.

Black, F. \& Scholes, M. (1973). The pricing of options and corporate liabilities. The Journal of Political Economy, 81(3), 637-654.

Campbell, J. Y., Lettau, M., Malkiel, B. G. \& Xu, Y. (2001). Have individual stocks become more

Carhart, M. M. (1997). On persistence in mutual fund performance. The Journal of Finance, 52(1), 57-82.

Carlin, B. P., Polson, N. G. \& Stoffer, D. S. (1992). A Monte Carlo approach to nonnormal and nonlinear state-space modeling. Journal of the American Statistical Association, 87(418), 493-500.

Chan, L. K., Jegadeesh, N. \& Lakonishok, J. (1995). Evaluating the performance of value vs growth stocks: the impact of selection bias. The Journal of Financial Economics, 38, 269-296.

Chen, N. F., Roll, R. \& Ross, S. A. (1986). Economic Forces and the Stock Market. The Journal of Business, $59(3), 383-403$.

Chiao, C. \& Hueng, C. J. (2005). Overreaction effects independent of risk and characteristics: Evidence from the Japanese stock market. Japan and the World Economy, 17(4), 431-455.

Coval, J. D. \& Shumway, T. (2005). Do behavioural Biases Affect Prices? The Journal of Finance, 60(1), 1-34.

Daniel, K. \& Titman, S. (1999). Market Efficiency in an Irrational World. Financial Analysts Journal, 55(6), 28-40.

Daniel, K., Hirshleifer, D. \& Subrahmanyam, A. (2001). Overconfidence, arbitrage, and equilibrium asset pricing. The Journal of Finance, 56(3), 921-965.

De Longe, J. B., Shleifer, A., Summers, L. H. \& Waldman, R. J. (1991). The survival of noise traders in financial markets. The Journal of Business, 64(1), 1-19.

Fama, E. F. \& French, K. R. (1993). Common risk factors in the returns on stocks and bonds. The Journal of Financial Economics, 33(1), 3-56.

Ferson, W. E. \& Harvey, C. R. (1993). The Risk and Predictability of International Equity Returns. Review of financial Studies , 6(3), 527-566.

Filimonov, V. \& Sornette, D. (2012). Quantifying reflexivity in financial markets: Towards a prediction of flash crashes. Physical Review, 85(5).

Friedman, M. (1953). The case for flexible exchange rates. In M. Friedman, Essays in Positive Economics. Chicago: University of Chicago Press.

Fu, F. (2009). Idiosyncratic risk and the cross-section of expected stock returns. The Journal of Financial Economics, 91, 24-37.

Harvey, C. R. (1989). Time-varying conditional covariances in tests of asset pricing models. The Journal of Financial Economics, 24(2), 289-317.

Hommes, C. (2001). Financial Markets as Nonlinear Adaptive Evolutionary Systems. The Journal of Quantitative Finance, 1(1), 149-167.

Huang, P. \& Hueng, J. C. (2009). Interest-Rate Risk Factor and Stock Returns: A Time-Varying FactorLoading Model. Applied Financial Economics, 19(22), 1813-1824.

Hume, D. (1975a). A Treatise of Human Nature (2 ed.). (L. A. Selby-Bigge, Ed.) Oxford: Clarendon Press.

Hume, D. (1975b). Enquiries concerning Human Understanding, in Enquiries concerning Human Understanding and concerning the principles of Morals (3rd ed.). (L. A. Selby-Bigge, Ed.) Oxford: Clarendon Press.

Jagannathan, R. \& Wang, Z. (1996). The Conditional CAPM and the Cross-Section of Expected Returns. The Journal of Finance, 51(1), 3-53.

Jegadeesh, N. (1990). Evidence of predictable behavior of security returns. The Journal of Finance, 45, 881-898.

Jegadeesh, N. \& Titman, S. (1993). Returns to buying winners and selling losers: implications for stock market efficiency. The Journal of Finance, 48(1), 65-91.

Jegadeesh, N. \& Titman, S. (2002). Cross-sectional and time-series determinants of momentum returns. The Review of Financial Studies, 15(1), 143-157.

Kandel, S. \& Stambaugh, R. F. (1991). Asset returns and intertemporal preferences. Journal of Monetary Economics, 27(1), 39-71. 
Keynes, J. M. (1936). The General Theory of Employment, Interest and Money. New York: Harcourt, Brace and Company.

Kogan, L., Ross, S. A., Wang, J. \& Westerfield, M. M. (2006). The price impact and survival of irrational traders. The Journal of Finance, 61(1), 195-228.

Lakonishok, J., Shleifer, A. \& Vishny, R. W. (1994). Contrarian investment, extrapolation, and risk. The Journal of Finance, 49(5), 1541-1578.

Lewellen, J. \& Nagel, S. (2006). The Conditional CAPM Does Not Explain Asset-Pricing Anomalies. The Journal of Financial Economics, 82(2), 289-314.

Levy, H. (1978). Equilibrium in an imperfect market: a constraint on the number of securities in the

Malkiel, B. G. \& Xu, Y. (2002). Idiosyncratic Risk and Security Returns. University of Texas at Dallas .

Markowitz, H. (1952). Portfolio selection. The journal of Finance, 7, 77-91.

Markowitz, H. M. (1991). Foundations of Portfolio Theory. The Journal of Finance, 46(2), 469-477.

Merton, R. C. (1987). A simple model of capital market equilibrium with incomplete information. The Journal of Finance, 42(3), 483-510.

Muth, J. F. (1961). Rational expectations and the theory of price movements. Econometrica: Journal of the Econometric Society, 3, 315-335.

Neely, C. J., Weller, P. A. \& Ulrich, J. M. (2009). The Adaptive Market Hypothesis: Evidence from the Foreign Exchange Market. The Journal of Financial and Quantitative Analysis, 44(2), 467-488.

Potters, M., Cont, R. \& Bouchaud, J. P. (1998). Financial Markets as Adaptive Systems. Europhysics Letters, 41(3), 239-244.

Rabin, M. (2000). Risk Aversion and Expected-utility Theory: A Calibration Theorem. Econometrica, 68(5), 1281-1292.

Rabin, M. \& Thaler, R. H. (2001). Anomalies: Risk Aversion. The Journal of Economic Perspectives, 15(1), 219-232.

Robinson, L. (2009). Ecological correlations and the behaviour of individuals. International Journal of Epidemiology, 38, 337-341.

Roll, R. (1977). A critique of the asset pricing theory's tests part 1: On past and potential testability of the theory. The Journal of Financial Economics, 4(2), 129-176.

Shiller, R. J. (2003). From Efficient Markets Theory to Behavioral Finance. The Journal of Economic Perspectives, 17(1), 83-104.

Sitkin, S. B. \& Pablo, A. L. (1992). Reconceptualizing the determinants of risk behavior. Academy of management review, 17(1), 9-38.

Slovic, P. E. (2000). The perception of risk. Earthscan Publications.

Trecroci, C. (2013). How Do Alphas and Betas Move? Uncertainty, Learning and Time Variation in Risk Loadings. The Oxford Bulletin of Economics and Statistics.

van Rensburg, P. (1999). Macroeconomic identification of candidate APT factors on the Johannesburg stock exchange. The Journal for Studies in Economics and Econometrics, 23(2), 27-52. 